\title{
Implementation of Google's Technology in Android Mobile App "Kediri City's Fasum and Fasos Information System"
}

\author{
Benni Agung Nugroho*1, Abidatul Izzah ${ }^{2}$ \\ 1,2Politeknik Kediri \\ benni.nugroho@gmail.com¹, abidatul.izzah90@gmail.com²
}

\begin{abstract}
There are so many public facilities (FasUm) and social facilities (FaSos) spreading all over the city. So that, many people do not know how to find and reach the location. Therefore, a mobile application becomes necessary to help solving problems in introducing and informing the location of those important facilities; thus, discovering and locating them can be simplified. This study aims to develop an android application providing information of public and social facilities. The application was built utilizing Google's features consisting of Google Sign In, Google Places API, Google Custom Search Engine, and Google Map. The application was developed in several steps; requirement analysis, system design, implementation, and testing. The application provides information, routes, related news, and location markers of public and social facilities from the app contributor and Google Services. The developed application has been compared with Google Map application. The result shows that it provides some features which are better than the existing app.
\end{abstract}

Keywords: Android Mobile Application, General Facilities, Google, Public Facility

\section{Introduction}

According to Indonesian dictionary, facility can be interpreted as a means to smoothen the implementation of the function. A facility consists of social and public facilities. Social facilities are facilities provided by government or private sector for communities, such as schools, clinics, and places of worship. While public facilities are facilities provided for public purposes, such as roads and public lighting equipment [1]. "Fasilitas Umum", also called FASUM, means public facility and "Fasilitas Sosial", also called FASOS, means social facility having various types and spreading across the city, as well as in Kediri city. Various facilities such as shopping, tourism (i.e. culinary tourism, nature tourism or other forms of tourism), health, banking facilities, transportation, sports, worship, educational facilities, and many others. The scattered FASUM and FASOS around Kediri City has caused people in Kediri and migrants do not know where to find those facilities and how to get there. Therefore, a mobile system or application that can search them anytime and anywhere will be very convenient. A mobile application, commonly shortened as an app, is an application running on smart phones, tablets or mobile phones. Kathuria [2] states that apps make mobile more become portable computers having multi core processors, gigabytes of memory and a real operating system. With the rapid increase in technology and user demands, developers started to make apps for other purposes like games, banking, video chats etc. Based on the user demand for how to find the nearest facility, this research has developed a simple and usefully mobile app on Android Operating System in this research.

In previous research, Nugroho [3][4] has developed a software being capable of recording data related to FASUM and FASOS information located in Kediri area. Moreover, the developed software is able to store the data location of the facilities and can find the closest route to reach them. However, the developed software has not been fully integrated with the technology provided by Google, so this research aims to develop more advanced system which is able to provide information and routes to FASUM and FASOS in Kediri on an Android-based mobile application integrated with technology from Google API services. In fact, in the previous studies [4], FASUM and FASOS information were just stored and complied by contributors and Google Places API. On the other hand, in this research, the features will be enhanced with the capability of searching the facilities, finding the nearest route and obtaining information related to a facility searched using Google search engine. Additionally, the contributors of this app are required to have Google's accounts. With the help of contributors, the FASUM and FASOS data obtained by contributors

Nugroho, B., \& Izzah, A. (2017). Implementation of Google's Technology in Android Mobile App "Kediri City Fasum and Fasos Information System". Kinetik : Game Technology, Information System, Computer Network, Computing, Electronics, and Control, 3(1). http://dx.doi.org/10.22219/kinetik.v3i1.543

Paper submitted on October 04, 2017; Revision on October 25, 2017; Received December 06, 2017 
will become data complement from those of gathered from Google. This study decided on utilizing Google due to its significant simplicity, practical benefits to the users and developers, and fast processing time. This research utilizes Google services and explores technical innovations, being in accordance to the nature of Google providing big concerns on innovation, service model, large user community, and the evolutionary nature of Computer Science research. Thus, in this research, Google Services are deeply explored to support the developed app [5].

\section{Research Method}

The app development in this research uses modified waterfall method. This process was started from the analysis of existing problems and then analyzed the problem solving by considering various variables. If the problem-solving analysis was accepted; afterwards, the following step was designing the system to determine how the app's components would be created.

The implementation phase by writing a program code or developing the app based on the proposed design would be executed. Once the application was successfully developed; consecutively, testing stage was performed. Testing was done by testers (users who had specific tasks to find bugs in the app), and in the case of discovered errors and problems in the app, the testers, afterwards, provided feedbacks to the developer. On the final stage when the app has been released to market/community, the process of maintaining the app should be done related with some processes of updating data and the application maintenance [6]. The stages of mobile application development process using modified waterfall method are illustrated in the following Figure 1.

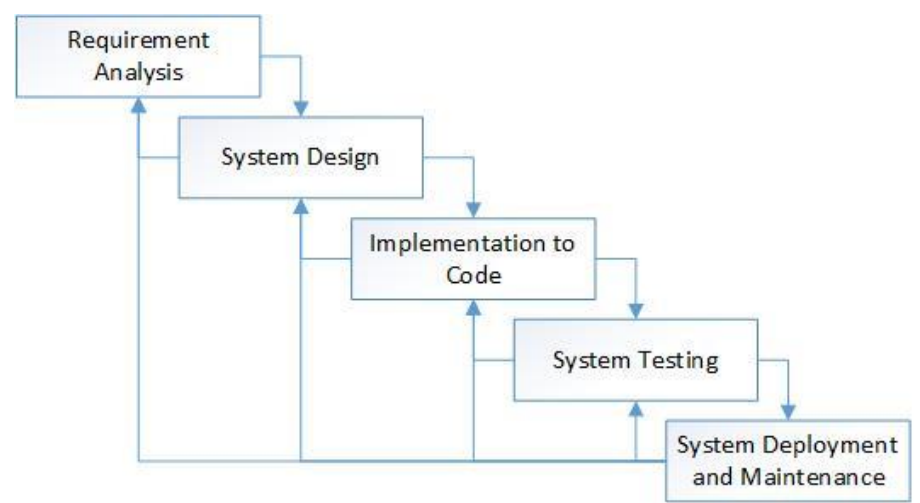

Figure 1. Software Development Employing Modified Waterfall Method

\subsection{Requirement Analysis}

Requirement analysis is a process for obtaining information, models and specifications about software desired by clients/users [6]. Furthermore, based on the requirement analysis that has been completed, this application requires 3 users, namely admin, contributor, and community. From these users, the functional needs can be proposed as follows:

1. Admin, the person managing all data. Admin has the following access rights:

- Admin can manage the data related to facilities, contributors, etc.

- Admin can verify data submitted by contributors, so admin can accept or reject data sent by contributors or perform CRUD (Create, Read, Update and Delete) operations on data.

2. Contributor, the party helping collecting data. The contributor role can be described as follows:

- Contributor can sign in into the app using a synchronized Google account with the device in use.

- Contributor can add new FASUM and FASOS information in the form of name, address, photo and some related description to the server

- Contributor can search information about public or social facilities just like ordinary user (community)

3. Community/user, users using the app and having the following permissions:

- User can search FASUM and FASOS by category or name.

- User can display FASUM and FASOS locations within the map in the form of markers.

- User can see the route that must be passed to arrive at designated FASUM and FASOS.

KINETIK Vol. 3, No. 1, February 2018: 45-56 
- User can access information related to the choosen FASUM and FASOS in the form of articles obtained based on Google search results.

- User can login into the app as a contributor by having a Google account.

\subsection{System Design}

\subsubsection{System Architecture Design}

From the requirement analysis previously described, the application was developed using a database server that could be accessed using JSON web service via internet to add or retrieve data contained therein. In addition, the app was developed using the help of technology provided by Google. As we know, Google Inc. [7] is a US multinational corporation that specializes in Internet services and products. These products include search technology, web computing, software, maps and online advertising.

Google has created services and equipment for business and community environment; including web applications, advertising networks and business solutions. The services used in developing Android based mobile apps include [8]:

\section{Google Maps API}

Google Maps launched in 2005 has revolutionized online mapping service applications on the World Wide Web. Based on Asynchronous JavaScript and XML (AJAX), a new type of client/server interaction was introduced in Google Maps to maintain a continuous connection between the client and the server for immediate downloading of additional map information [9]. This Google service works to display maps with multiple location markers. In addition, this service is used to represent the location, path, and geography points of FASUM and FASOS. Displaying Google Maps on Android uses the following program code:

GoogleMap gMap;

mapFrag = (MapFragment)getFragmentManager().findFragmentByld(R.id.gmap);

\section{Google Sign In API}

Google service eases its users to synchronize data or accounts that have been registered with Google utilizing Android apps. With this service, the users do not need to re-enter personal information required to access the contributor page. To use this service, the following source code is used:

GoogleSignInOptions googleSignInOptions = new

GoogleSignInOptions.Builder(GoogleSignInOptions.DEFAULT_SIGN_IN).requestEmail().build();

GoogleApiClient googleApiClient $=$ new

GoogleApiClient.Builder(this).enableAutoManage(this,this).addApi(Auth.GOOGLE_SIGN_IN_API,googleSignInOp tions).addApi(Applndex.API).build();

\section{Google Places API}

This Google service provides location information stored in Google's database. This technology allows users to compare data from Google and those of the contributors. Thus, both sources will complement each other FASUM and FASOS information. Accessing information on desired places in the Google database utilizes the following code:

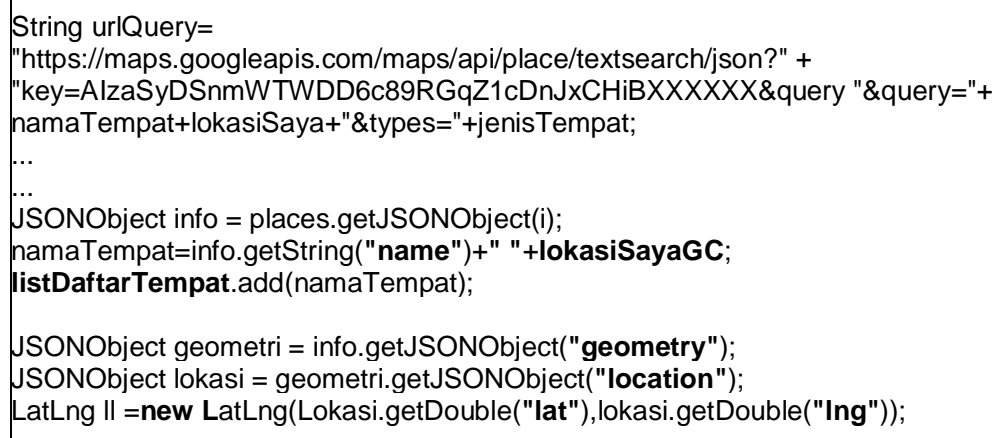




\section{Google Custom Search Engine API}

This Google service is used to link related news about the selected FASUM and FASOS. This linking is used so that users can see the most updated information based on Google search results. To access the news searched, the following code is used:

String urllnfoSearchEngine = "https://cse.google.com/cse/publicurl?cx=008857059344802905492:" +

"wkihutrjvm8\&ie=UTF-8\&q="; ...

webView.loadUrl(urllnfoSearchEngine+URLEncoder.encode(id))

\section{Android Operating System}

Android is an operating system for Linux-based mobile devices including operating systems, middleware, and applications. Android provides an open platform for developers. According to Meng [10], Android is referred to as the first complete, open, and free model platform for the following reasons:

1. Complete (Complete Platform): The designers can take a comprehensive approach when they are developing an Android platform.

2. Open (Open Source Platform): Android platform is provided through an open source license. Developers can freely develop applications without prior permission.

3. Free (Free Platform): Android is a free platform. No licenses or royalty fees needed to be submitted in developing Android apps. In addition, there are no membership fees, contracts, and testing fees. Applications for android can be freely distributed and traded in any forms.

4. To develop an android app, it takes Android Software Development Kit. Android SDK provides the Tools and APIs required to develop applications on the Android platform using Java programming language. Until now, it has been compiled several Android versions that have been launched, and the most recent version when this study conducted is the Oreo version [11].

Based on the technology used, the architecture of the built system is shown by the Figure 2 .

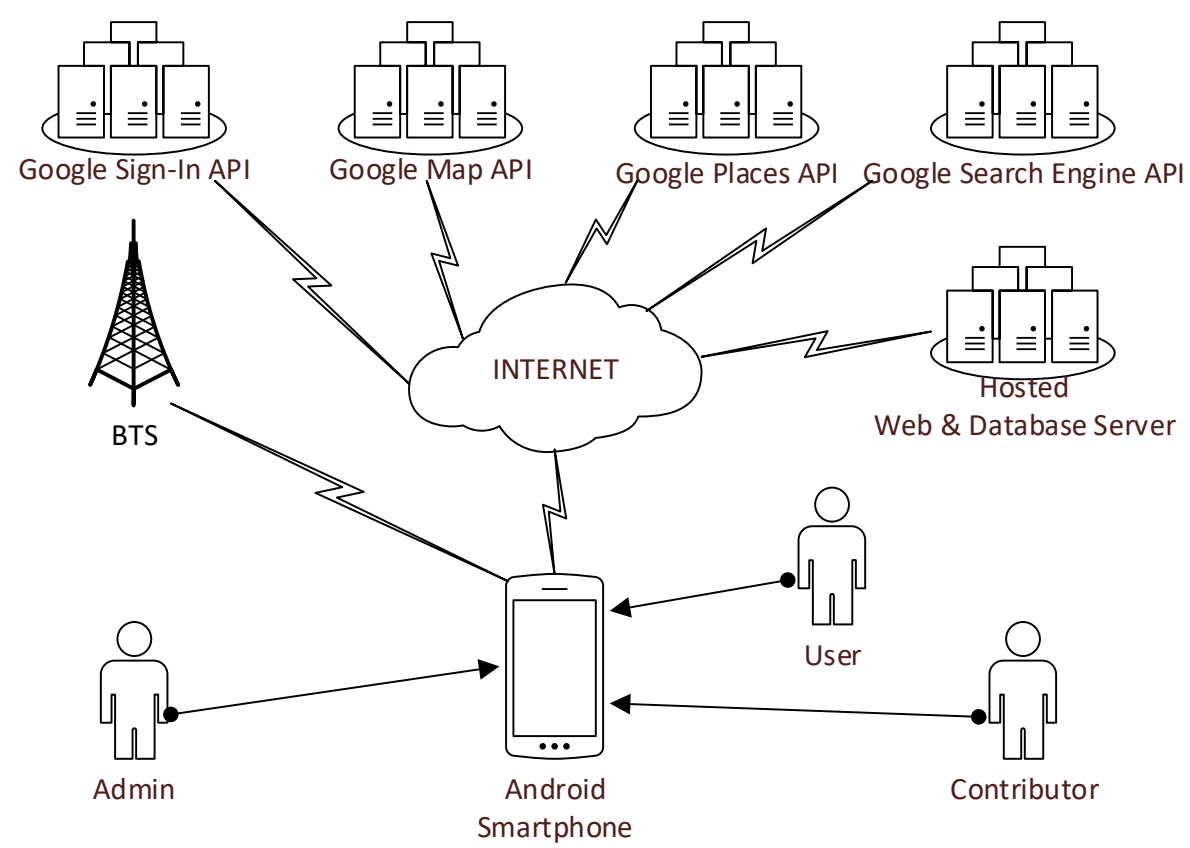

Figure 2. Architecture of System Design

\subsubsection{Bussiness Process}

Business Process is a collection of interrelated activities to solve a particular problem [6]. To use this application, Figure 3 presents the user application flow.

KINETIK Vol. 3, No. 1, February 2018: 45-56 


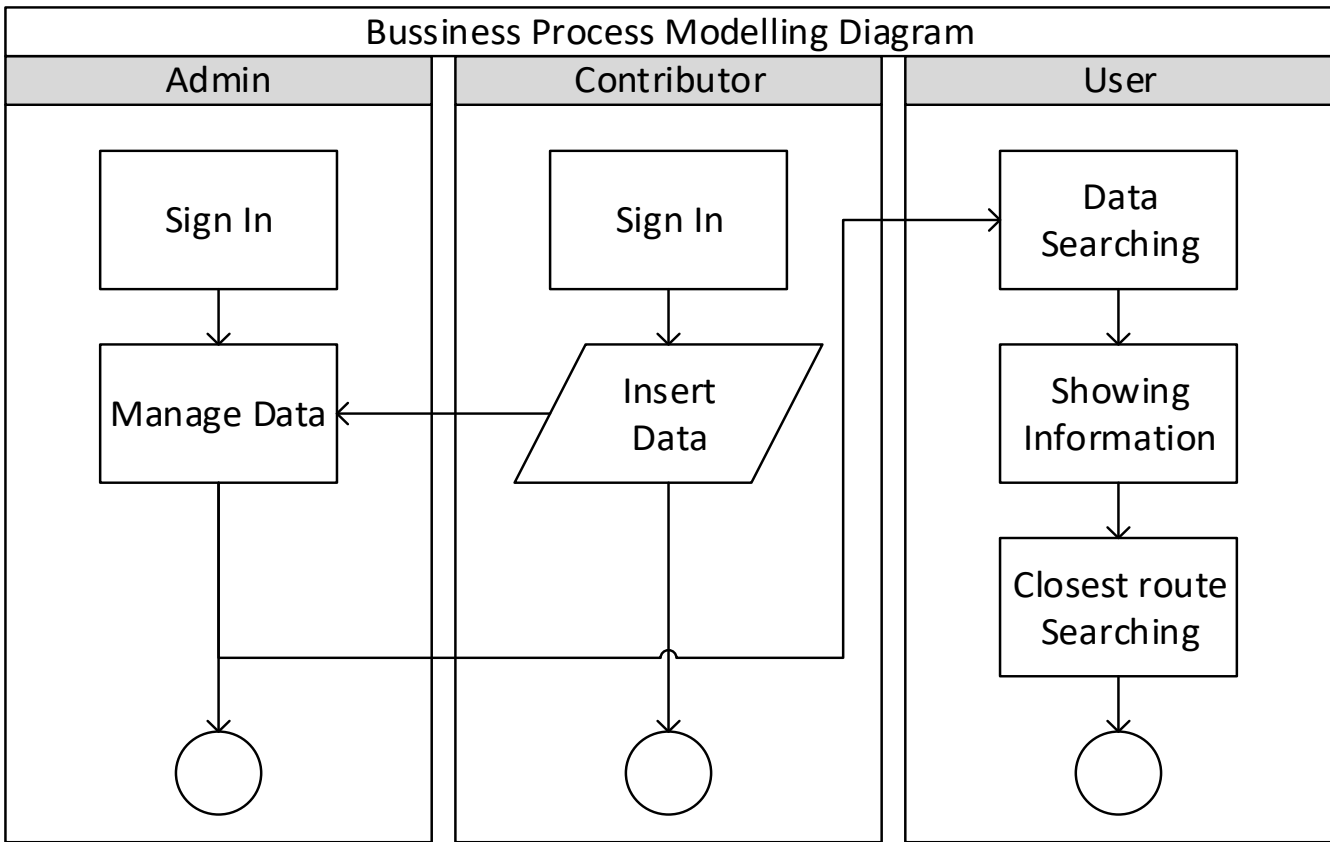

Figure 3. Bussiness Process

\subsubsection{Database Design}

To save the data required by application, five entities will be needed to store information that is used. Those entities are jenis_tempat (type of place), tempat (place), propinsi (province), kota_kab (city/district), and user. From those entities, afterwards five tables are developed as follows:

1. Table jenis_tempat is used to store data in the form of type of place;

2. Table tempat is used to store information about public and social facilities;

3. Table propinsi is used to store information about the names of provinces;

4. Table kota_kab is used to store information about the names of cities or districts, and;

5. Table user is used to store information about the contributor.

The relationship between tables that has been previously described is shown in Figure 4 .

\begin{tabular}{|c|c|c|c|c|c|}
\hline \multicolumn{2}{|c|}{ jenis_tempat } & \multicolumn{2}{|c|}{ tempat } & \multicolumn{2}{|c|}{ user } \\
\hline id_jenis_tempat & integer(11) & Sy id_prop & integer(11) & Pid_user & \multirow{2}{*}{$\begin{array}{l}\text { varchar(16) } \\
\text { varchar(6) }\end{array}$} \\
\hline \multirow{2}{*}{ Jenis tempat } & \multirow[t]{2}{*}{$\operatorname{varchar}(100) \quad \mathbf{U}$} & Tid_prop & integer(11) & \multirow{3}{*}{$\begin{array}{l}\text { password } \\
\text { nama_user } \\
\text { jenis_id }\end{array}$} & \\
\hline & & 圆 lat & double(10) & & $\operatorname{varchar}(30)$ \\
\hline \multicolumn{2}{|r|}{ propinsi } & Ing & double(10) & & integer(11) \\
\hline Pid_prop & integer(11) & image & varchar(26) & \multirow{3}{*}{$\begin{array}{l}\text { no_id } \\
\text { alamat } \\
\text { 亶 email }\end{array}$} & varchar(20) \\
\hline \multirow{3}{*}{\multicolumn{2}{|c|}{ nama_prop varchar(45) }} & 目 alamat & $\operatorname{varchar(50)}$ & & varchar(60) \\
\hline & & 目 telp & varchar(12) & & varchar(30) \\
\hline & & keterangan & $\operatorname{varchar}(250)$ & $\infty$ & \\
\hline \multirow{2}{*}{\multicolumn{2}{|c|}{$\frac{1}{\phi}$}} & 囬 nama_tempat & $\operatorname{varchar}(30)$ & & \\
\hline kota_kab & & tgl_input_data & integer(10) & & \\
\hline \multicolumn{2}{|c|}{ P' id_kota_kab integer(11) } & \multirow{3}{*}{$\begin{array}{l}\text { 7q id_enis_tempat } \\
\text { id_user } \\
\text { 面 aktif }\end{array}$} & integer(11) & & \\
\hline Thid_prop & integer(11) & & varchar(16) & & \\
\hline 直 nama_kota & $\operatorname{varchar}(60)$ & & 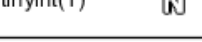 & & \\
\hline
\end{tabular}

Figure 4. Database Design

\section{Results and Discussion}

The system testing process was completed to check and review whether the developed app can be run according to meet the users' needs. two testing scenarios were needed in this stage, namely, testing the use of Google Technology and testing the user needs. 


\subsection{Result}

\subsubsection{Google Services Testing}

\subsubsection{Google Maps API}

Google Maps technology is used on display the app's start page. A Google Maps page will appear when the app starts up. The page will display the coordinates of the Android device running the app. Figure 5 shows a map showing the current position of an Android device based on the coordinates obtained from the GPS. The blue marker shows the current location of the device on Geolocation positioning.

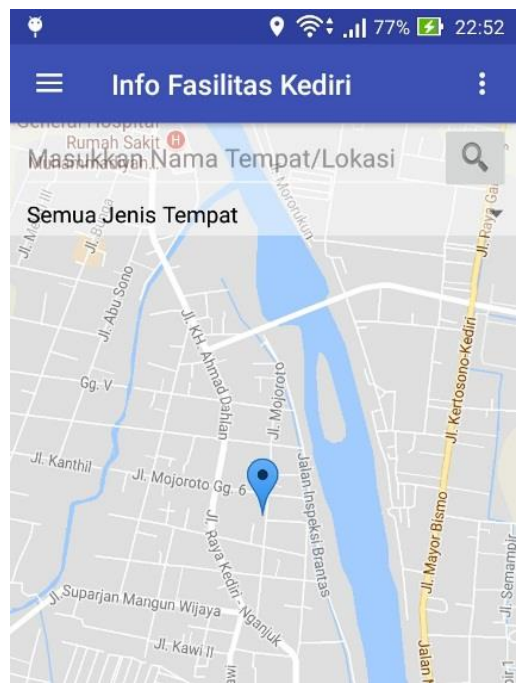

Figure 5. Showing Current Device Location on Map

\subsubsection{Google Places API}

Google Places API technology is used to retrieve places stored in Google's database. The data from Google will be displayed and compared to the data collected by the contributors. For example, Figure 6a shows placemarks with the keyword "SMA Negeri 2 Kediri" colored red and green. The red marker represents the data collected by the contributors while the green marker represents data retrieved from Google's database using the Google Places API. In addition, Google Places API can be utilized to search for places according to its specific type as shown in Figure 6b. Moreover, Google Places API is requested to search for "university" type places. Meanwhile, Figure $6 \mathrm{c}$ displays a list of universities from the search results.

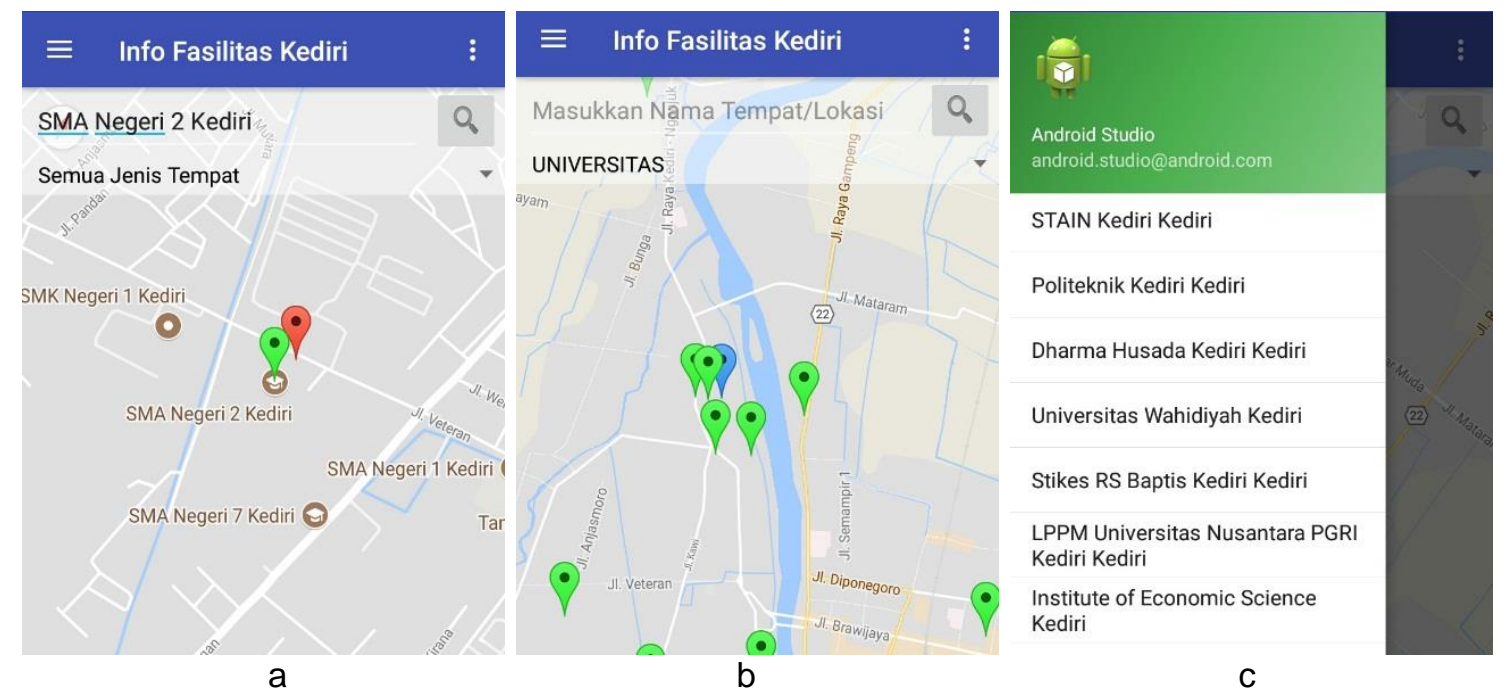

Figure 6. Searching Places Using Google Places APl: (a) Searching Places by the Name of Place, (b) Searching Places by the Type of Place, (c) Showing the Name of Places from the Search Result 
1. Google Search Engine API

Google Search Engine service is employed to search for FASUM and FASOS related articles or news. Articles or news are obtained based on Google search results with the the name keyword of facility or place. From the previous test, in the selection of the green marker, it would be directed to articles or news related to "SMA Negeri 2 Kediri" as shown in Figure 7. Google search results were displayed in the form of web pages (Figure 7a) and pictures (Figure 7b).

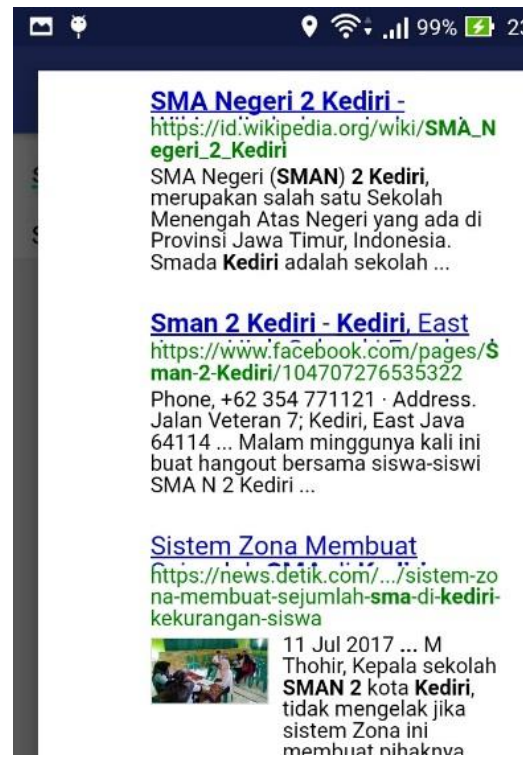

a

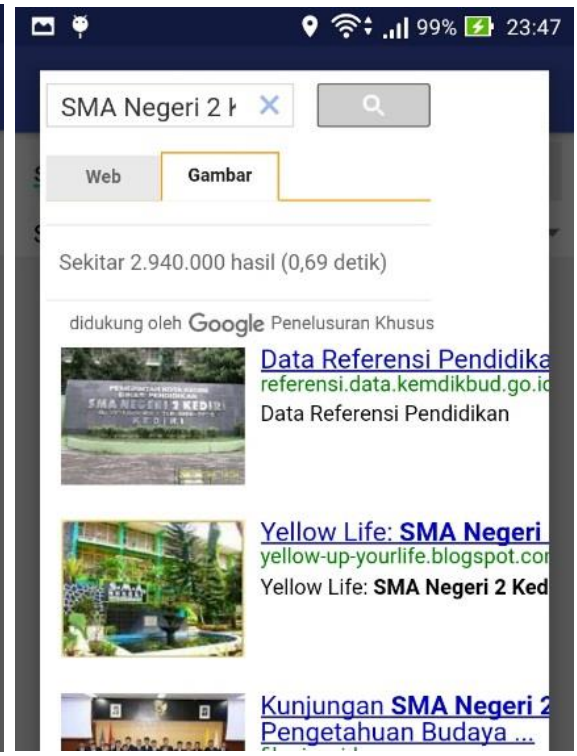

b

Figure 7. Implementation of Google Search Engine API: (a) Search Results Displayed in the Form of Web Pages; and, (b) Search Results Displayed as Pictures

\section{Google Sign In API}

This service is used to make ease recording function of contributors' data who participate in providing FASUM and FASOS information. By using this service, information about contributors is recognized. The signing process can be seen in Figure 8. Contributors can press the login button (Figure 8a) which will then be directed to select the Google account used to participate in providing FASUM and FASOS data (Figure 8b). After a successful login, the data collection page will be displayed as presented in Figure 8c.

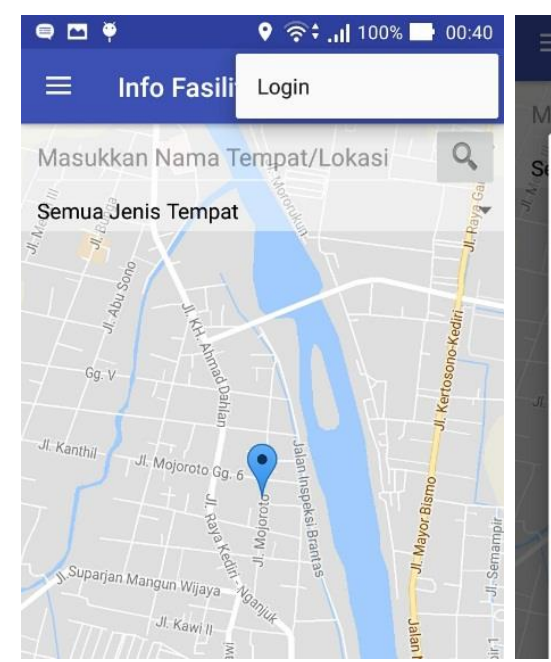

a

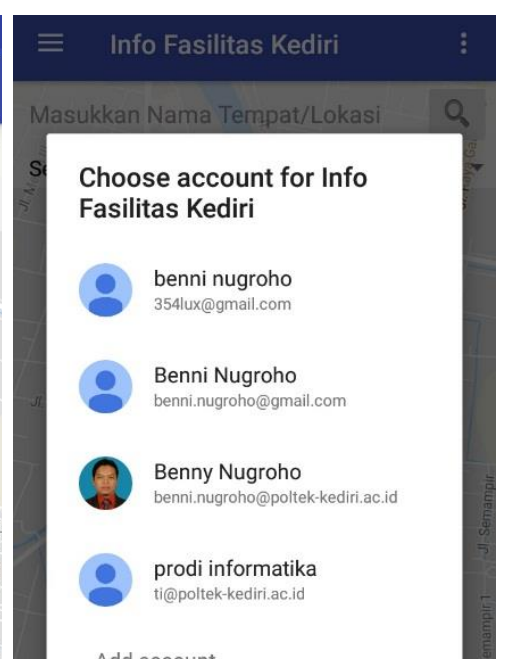

$\mathrm{b}$

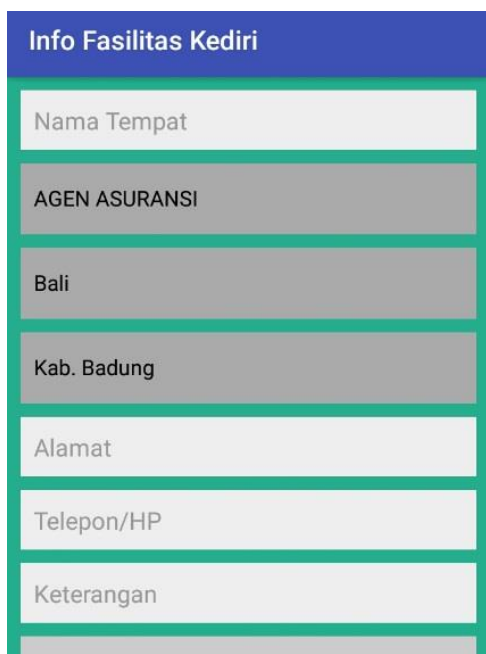

C

Figure 8. Implementation of Google Sign In API: (a) Login Button; (b) Choosing Google Account for Login as Contributor; and (c) Input Data Page 


\subsubsection{Application Features Testing}

Testing of application features is an application test that has been developed in the previous research [3] and [4]. The following information conveys the testing processes of some of the application features provided:

\section{Input Data Testing}

Input data testing is completed after the contributor successfully login into the application. For example, a trial was conducted to enter the data of public facilities -- namely "Taman Ngronggo" (Ngronggo Park) with the category "Taman" (Park) as shown in Figure 9a. After the data was successfully entered, the searching results for a place called "Taman Ngronggo" could be displayed into the map as a red marker as depicted in Figure 9b.
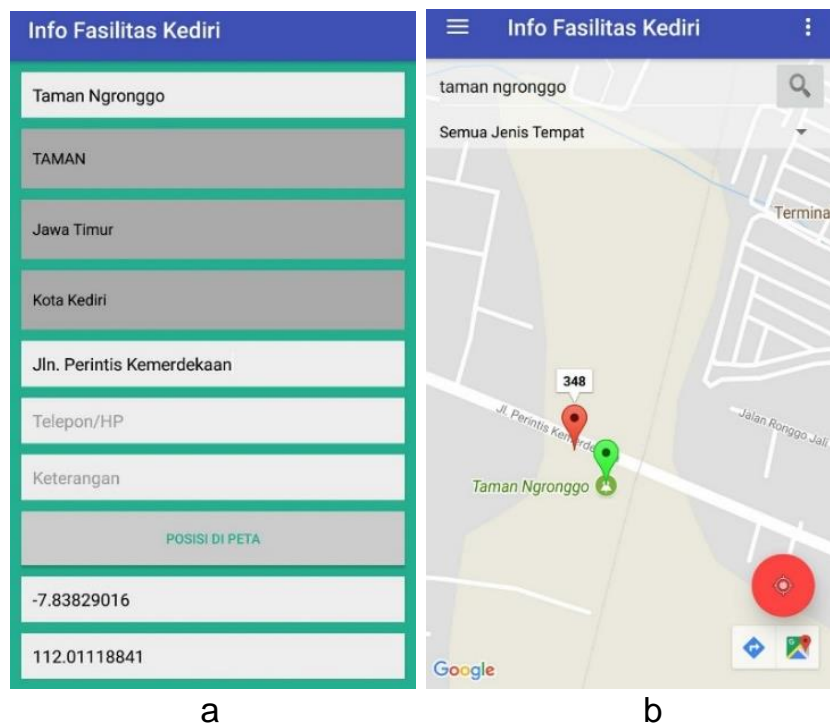

Figure 9. Testing of Entering Facility Data: (a) Input Page for Entering New Facility Data; (b) The Location of the Facility Displayed in the Map as a Red Marker

\section{Data Searching Testing}

Data searching testing is executed by entering keywords or categories of facilities to be searched. For example, the search process would be carried out by using the newly incorporated facility data "Taman Ngronggo". Figure 10a presents a list of search results displaying the data collected by the contributors and the data extracted from Google Places database. When the data from Google was selected, it would display related news or articles to the selected data (if any) as shown by Figure 7. Nevertheless, if data from contributor was selected; afterwards, the app would display information according to the data collected by the contributors, as well as displaying related news or articles obtained from Google search engine as shown in Figure 10b.

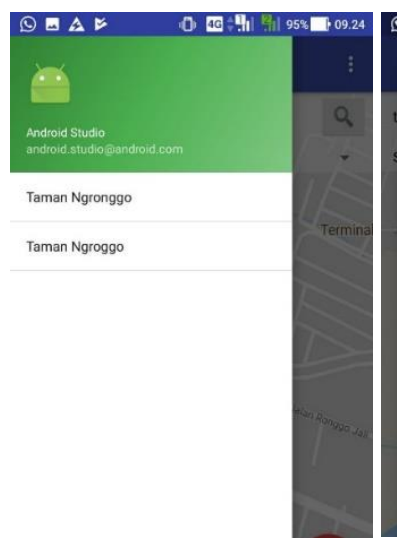

a

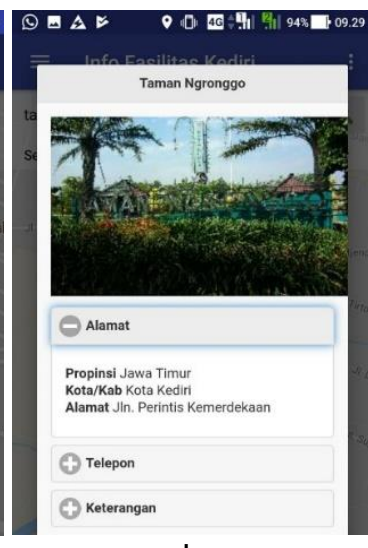

$\mathrm{b}$

Figure 10. Data Search Results: (a) Displaying Search Results; and (b) Displaying the Information of the Selected Place

KINETIK Vol. 3, No. 1, February 2018: 45-56 
3. Closest Route Searching Testing

This feature is available by selecting the chosen location that will be visited. For example, a trial run showed the route to "Taman Ngronggo" from the current user position. The route search could be completed by pressing the "Get Direction" button as shown in Figure 11a. Sub sequentially, Google Map would search and display the closest route to the selected location as shown in Figure 11b.
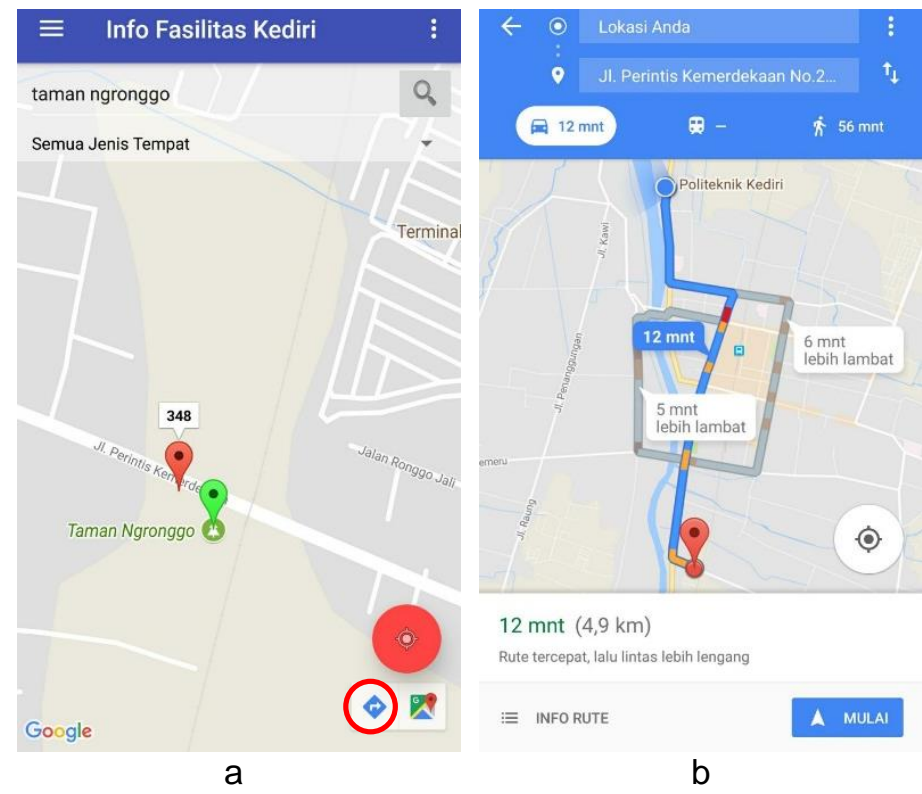

Figure 11. Searching the Closest Route: (a) Displaying "Get Direction" Button; and (b) Displaying the Closest Route to the Destination

\subsubsection{Comparison with Google Map App}

In this stage, the developed app will be compared with that of the Google. The user interface and feature app will be compared to measure the reliability of how the developed app.

\section{User Interface}

In both apps, user can add some data. The interfaces can be seen in Figure 12. Based on the picture, Google has more flexible information form. Google also provides the function of altering the marker according to the contributor's needs. Whereas in the developed app, the location information is taken from Geolocation services and automatically displays the current contributor's location. Conclusively, it is considered as less flexible according to the constituent's needs to add a location that is not being occupied.

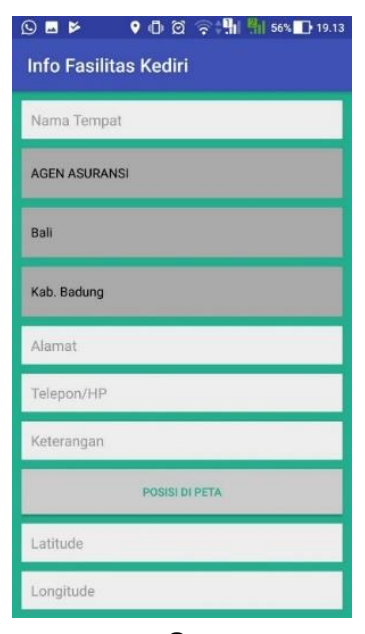

a

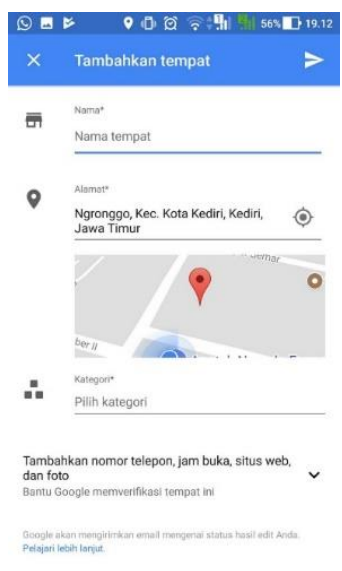

b

Figure 12. Input Data Interfaces: (a) Developed App; and (b) Google Map App 
On the other hand, the marker display will also be compared as presented in Figure 13. Based on the pictures, the developed app shows more informative marker. In Figure 13a, the blue marker indicates the current location from an app user. The red marker shows the data collected by the contributors, and the green marker shows the data retrieved from Google database. While in Figure 13b, Google Map displays the same marker symbol for all data from the contributors and from Google database. In order to show the user's position, Google Map app utilizes a blue circle symbol.

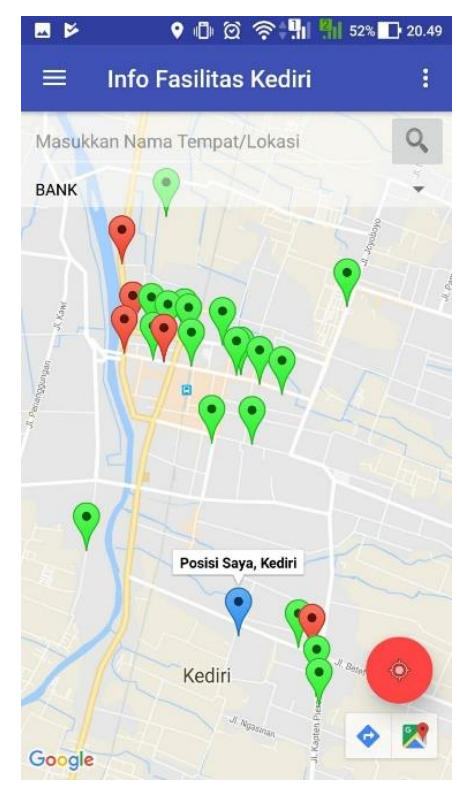

a

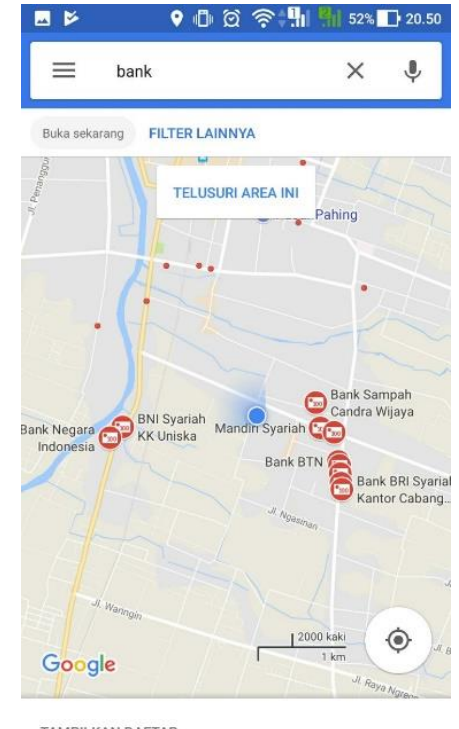

b

Figure 13. Marker Display Interfaces: (a) Developed App; and (b) Google Map App

\section{User Feature}

In both apps, users can obtain data information. When a user adds some data (as a contributor), both apps will show identical categories as shown in Figure 14a. Moreover, the categories in the developed app can also be updated by a web administrator. However, when a user searches for data, Google Map shows only 6 location categories (Figure 14b).

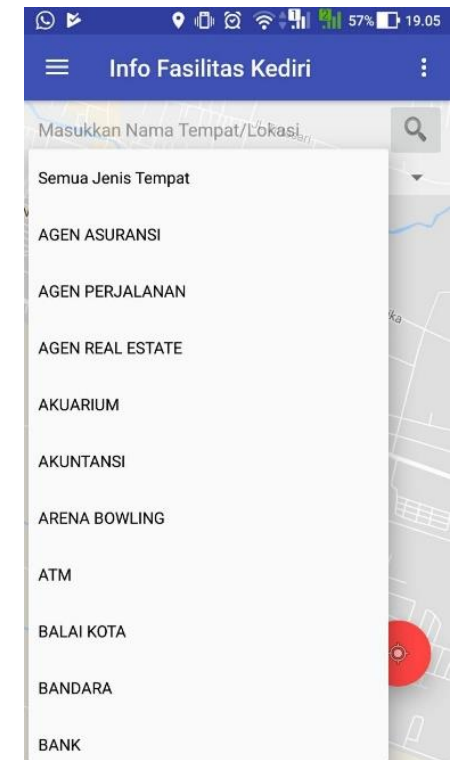

a

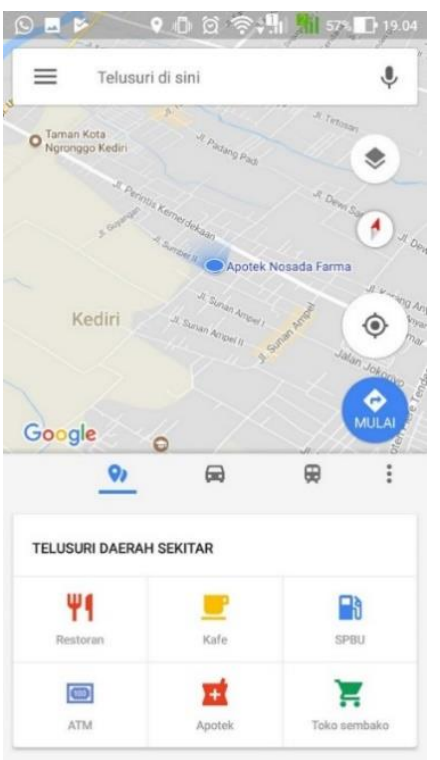

$\mathrm{b}$

Figure 14. Location Categories: (a) Developed App: and (b) Google Map App 
On the other hand, a user feature being available in the developed app displays related news links. It is considered as a unique feature which cannot be not found in Google Map app. This feature utilizes Google search engine services as described in section 3.1 by Figure 7 .

\subsection{Discussion}

After testing the overall system was conducted, then the system was tested using Black Box Testing concept. Black box testing is a testing method prioritizing the test on the functional requirements of a program [12]. The purpose of this Black Box Testing method is to find the function errors in the program. Testing with Black Box Testing method was completed by giving some inputs to the program. The inputs were then processed in accordance with its functional requirements to determine whether the application program could produce desired outputs and in accordance with the basic functions of the program. Table 1 shows the evaluation results of all functional requirements that have been previously determined.

Table 1. Requirement Analysis Test

Features

Admins can manage the facility and contributor data

Admin may verify data submitted by contributors

Contributors can sign into the app using a Google account

Contributors may enter new data on facilities

People can search FASUM and FASOS by category

Public can obtain the location of FASUM and FASOS in the map in the form of markers

Users can see the route leading to FASUM and FASOS

People can see related information to FASUM and FASOS in

the form of articles or news obtained from Google search

engine and in the form of information supplied by the

contributors

However, to measure how reliable the developed app, a comparison test with those of Google was conducted. The comparison results are presented in Table 2.

Table 2. Results of Comparison Test

\begin{tabular}{ccc}
\hline Indicator & Google Map App & Developed App \\
\hline Input form & More flexible form & Less flexible form \\
Marker & Less representative & More representative \\
Categories & 6 categories & Capable to grow \\
News related & Not available & Available \\
\hline
\end{tabular}

\section{Conclusion}

Based on research conducted, the application has been successfully developed to provide information related to FASUM and FASOS in Kediri in the form of Android mobile application integrated with Google technology. This app are used by 3 different users, namely admin, contributor, and community. Moreover, the features provided by the app include searching public and social facilities, searching the shortest route to the chosen facility, displaying related information based on Google search results and additional information from contributors. The app built in this research is integrated with Google services including Google Sign In, Google Places, Google Custom Search Engine, and Google Maps. The developed app also has been compared with Google Map app. The results show some unique features which are better than the existing app. The developed app is expected to help the community in finding the location of FASUM and FASOS around Kediri. Furthermore, this application can be developed and marketed thoroughly to the public.

\section{References}

[1] Indonesian Dictionary, on page kbbi.web.id.

[2] Kathuria, A., Gupta, A., "Challenges in Android Application Development: A Case Study", International Journal of Computer Science and Mobile Computing, Vol. 4, Issue 5, Pp. 294 299, 2015. 
[3] Nugroho, B.A., "Android-based Application Development on Public Facility Information System in Kediri to Improve the Society and Newcomer Access," Information and Multimedia Journal, Vol. 7, No. 1, Pp. 8-12, 2015.

[4] Nugroho, B.A., and Izzah, A, "Geolocation and Cloud Computing-based Mobile Application Development on FASUM and FASOS Information in Kediri to Improve Public Service," The Proceedings of National Seminar in Information, Universitas Merdeka Malang, Pp. 554 $564,2017$.

[5] Spector, A., Norvig, P., and Petrov, S., "Google's Hybrid Approach to Research" Communications of the ACM, Vol. 55, Issue 7, Pp. 34-37, 2012.

[6] Pressman, and Roger S., "Software Engineering: Practical Approach (Book One)," Andi Offset, 2002.

[7] Google, on page https://www.google.com/int//en/about/ accessed on September $3^{\text {rd }}$, 2017.

[8] Developer Google, on page https://developer.google.com accessed on September $3^{\text {rd }}$, 2017.

[9] Peterson, M. P., "International Perspectives on Maps and the Internet: An Introduction", International Perspectives on Maps and the Internet, Pp. 3-10, 2008.

[10] Meng Lee W., "Android Application Development: 92 Recipes for Building Winning Apps," John Willey \& Sons Inc., 2013.

[11] Android Open Wonder, Introducing Android 8.0 Oreo, on page https://www.android.com/versions/oreo-8-0/ accessed on September $3^{\text {rd }}, 2017$.

[12] Romeo, "System Testing and Implementation," $1^{\text {st }}$ Edition, STIKOM, 2003. 